DOI https://doi.org/10.15589/znp2019.2(476).2

УДК 629.5:624.04

\title{
STUDY OF STRESS-STRAIN STATE OF A FREE GIRDLE OF A BEAM WITH BREAK OF A WEB
}

\section{ДОСЛІДЖЕННЯ НАПРУЖЕНО-ДЕФОРМОВАНОГО СТАНУ ВІЛЬНОГО ПОЯСКУ БАЛКИ ЗІ ЗЛАМОМ СТІНКИ}

\author{
Valerii M. Sokov \\ valera.sokov@gmail.com \\ ORCID: 0000-0003-3933-879X
}

\author{
В. М. Соков, \\ наук. співробітник, асистент
}

Admiral Makarov National University of Shipbuilding, Mykolaiv

Національний університет кораблебудування імені адмірала Макарова, м. Миколаїв

\begin{abstract}
Purpose. In the article the ground of energy method of investigation of stress state of metal beam with abrupt change of web height and girdle is presented to get if possible simple dependencies for effective width of free girdle at inclined region in place of transition of smaller web height to larger one and for optimal design of such beam on the whole, for these dependencies to be applied in simple formulae of strength of materials at engineering calculations using simplified beam and rod models.

Method. There is presented on the simple example of plane problem of the theory of elasticity for rectangular plate at action of self-balanced shear external loads on it applied to mutual opposite edges the application of energy method and classic approach for definition of effective width of plate in its middle part, comparison of these methodologies between itself, the discussion and analyzing of findings. Investigations of stress-strain state of plate were provided by finite element method and using analytical solution.

Results. There is shown high similarity of dependencies of full elastic energy of plate and effective width of plate on real width, despite these dependencies have different physical nature and units of measure. The particularity of inclined part of free girdle of observed beam is that the plane stress state is not realized completely there, because there is warping of free girdle and as the result complex stress-strain state and that's why classic idea of effective width don't work completely. The circumstance is complicated by the fact that the stress state on upper and lower surfaces of girdle of inclined zone is different, but stress concentration in the place of transition from smaller web height to inclined zone input its correctives into stress state of this field. This circumstance made to look for alternate ways of taking into account of work of girdle on the inclined part.

Scientific novelty. It is offered applying of energy method meaning using an elastic energy dependency of a free girdle (or its part) on its geometrical parameters for development of relations of effective width and for optimal design, because elastic energy consider all parts of stress-strain state.

Practical importance. The possibility of application of energy method both as auxiliary to classic one and as independent for development of mentioned above relations is shown.

Key words: effective width of flange; beam with break of web and girdle; reduction factor of girdle; beam with broken axis; beam of a broken contour; thin-wall nonprismatic beam; I-section; T-section.
\end{abstract}

Анотація. Мета. У роботі представлено обгрунтування енергетичного методу дослідження напруженого стану металевої балки з різкою зміною висоти стінки та пояску з метою отримання по можливості простих залежностей для ефективної ширини вільного пояску на похилій ділянці в місці переходу від меншої висоти стінки до більшої та оптимального проектування такої балки загалом, щоб ці залежності можна було застосовувати у простих формулах опору матеріалів при інженерних розрахунках за спрощеними балочними та стержневими моделями.

Методика. На простому прикладі плоскої задачі теорії пружності для прямокутної пластини при дії на неї самоврівноважених дотичних навантажень, прикладених до взаємопротилежних кромок, показано застосування енергетичного методу і класичного підходу для визначення приведеної ширини пластини в їі середній частині, порівняння цих методів між собою, проведено обговорення й аналіз отриманих результатів. Дослідження напружено-деформованого стану пластини проводилося методом скінченних елементів і з використанням результатів аналітичного рішення.

Результати. Показна висока подібність залежностей повної пружної енергії пластини й ефективної (приведеної) ширини пластини від дійсної ії̈ ширини, незважаючи на те, що ці залежності мають різну фізичну природу 
i розмірності. Особливістю похилої ділянки вільного пояску досліджуваної балки $є$ те, що там повністю не реалізовується плоский напружений стан, бо на ній має місце депланація вільного пояску i, як результат, складний напружено-деформований стан, і тому класична ідея ефективної ширини тут не працює повною мірою. Ускладнює обставину те, що напружений стан на верхній і нижній поверхнях пояску похилої зони $є$ різним, а концентрація напружень в місці переходу від меншої стінки до похилої зони вносить свої корективи у напружений стан цієї області. Саме ця обставина змусила шукати альтернативні шляхи врахування роботи пояску на похилій ділянці.

Наукова новизна. Запропоновано застосування енергетичного методу, що полягає у використанні залежності пружної енергії вільного пояску (або його частини) від його геометричних параметрів для розробки залежностей приведеної ширини й оптимального проектування, оскільки пружна енергія враховує всі складники напружено-деформованого стану.

Практична значимість. Показана можливість використання енергетичного методу як допоміжного до класичного та самостійного для розробки залежностей вищеназваних величин.

Ключові слова: ефективна (приведена) ширина пояску; балка зі зламом стінки і пояску; редукційний коефіцієнт пояску; балка зі зламом осі; балка ламаного обрису; тонкостінна непризматична балка; I-переріз; Т-переріз.

\section{ПОСТАНОВКА ЗАДАЧІ}

У складі корпусу судна особливе місце займають балки з різкою зміною висоти стінки (рис. 1), які однією з кромок кріпляться до настилу, а до іншої кромки кріпиться вільний поясок, для забезпечення стійкості при дії стискуючих осьових сил і плоскої форми згину, підвищення осьового моменту опору, що, як результат, призводить до збільшення міцності та жорсткості при згині.
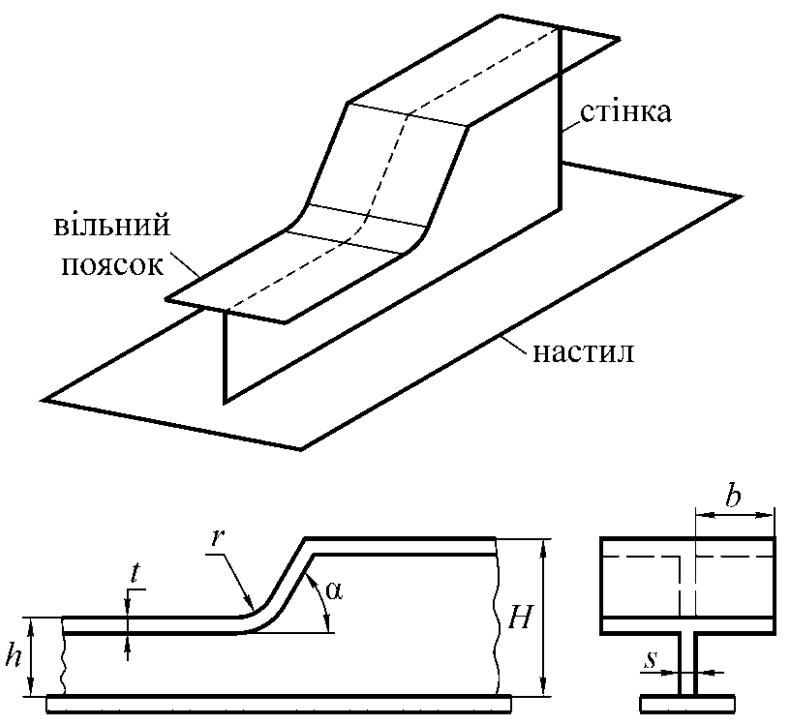

Рис. 1. Загальний вигляд досліджуваної балки зі зламом стінки і пояску

Вищезгадана балка, зображена на рис. 1, є об’єктом дослідження ії напружено-деформованого стану (НДС) при пружному та пружно-пластичному деформуванні з метою розробки оптимальних (i по можливості простих) методик проектування цього вузла. Дослідження міцності цього вузла має декілька незалежних напрямів, один із яких розглядається нижче.

У нашій роботі увага присвячена обговоренню методів дослідження ефективної ширини вільного пояску при осьовому розтягуванні, та проблемам, які виникають.

\section{ВІДОКРЕМЛЕННЯ НЕВИРІШЕНИХ РАНІШЕ ЧАСТИН ЗАГАЛЬНОЇ ПРОБЛЕМИ}

У загальних курсах будівельної механіки та теорії пружності розглядаються питання про редукційний коефіцієнт $\psi$ пояску прямої балки постійного перерізу та його відповідну ефективну ширину $b_{\text {пр}}$, які взаємопов'язані залежністю

$$
b_{\text {пр }}=\psi b,
$$

де $b$ - дійсна ширина пояску.

Формула (1) справедлива для випадків, коли поясок балки знаходиться у плоскому напруженому стані.

Як показують попередні дослідження, формула (1) не може бути безпосередньо застосована до балки зі зламом стінки на похилій ділянці в місці переходу від малої висоти стінки до великої, що розглядується в цій роботі і показана на рис. 1, оскільки в районі зламу стінки НДС у вільному пояску вже не є плоским, бо залежить від відношення висот більшої та меншої стінок і кута нахилу, і на цій похилій ділянці пояску має місце депланація. Загалом редукційний коефіцієнт буде змінним вздовж довжини балки і залежатиме від таких параметрів, як реальна ширина вільного пояску $b$, товщина вільного пояску $t$, кут нахилу кромки $\alpha$, радіус скруглення $r$, висоти стінок $H$ i $h$. Лише в окремих випадках, коли кут $\alpha$ доволі малий (не більше 10-15²), для визначення приведеної ширини пояску може бути застосована наближена формула проф. В.П. Суслова.

$$
b_{\text {пр }}=\frac{b}{1+0,14 \frac{b}{t} \sin \alpha},
$$

яка наведена в [1]. Формула (2) потребує додаткового аналізу та дослідження. 
У доповіді [2] був озвучений один зі шляхів для визначення ефективної ширини пояску балки зі зламом стінки - застосування т. зв. методу залежності повної пружної енергії вузла (або деякої частини вузла, наприклад, пояску) від його геометричних параметрів, запропонованого автором. Суть його полягає в тому, що для вільного пояску визначається повна енергія пружного деформування залежно від його геометричних параметрів. Додатково можна визначати середню питому енергію пружного деформування, що становить відношення повної пружної енергії пояску до об’єму цього самого пояску. Було висунуто припущення, згідно з яким при зміні (поступовому збільшенні чи зменшені) деяких параметрів пояску, починаючи 3 певних їх значень, величина пружної енергії стабілізується, означаючи, що подальше поступове зменшення або збільшення значень обраних параметрів після стабілізації енергії не має сенсу, оскільки несуча спроможність цієї конструкції не збільшується. Подальші дослідження чисельними методами, проведені на вузлі, підтвердили це припущення. Навіть для плоскої задачі теорії пружності для прямокутної пластини, розглянутої нижче, воно має місце і для багатьох випадків параметричного проектування конструкцій.

\section{АНАЛІЗ ОСТАННІХ ДОСЛІДЖЕНЬ І ПУБЛІКАЦІЙ}

На основі робіт, присвячених дослідженню напружено-деформованого стану тонкостінних балок, можна зробити висновок, що загалом простежується тенденція або розвитку ідеї ефективної ширини, або відмови від цієї ідеї взагалі і запровадження інших альтернативних величин, що враховують нерівномірність розподілень напружень при складному навантаженні. У більшості робіт, присвячених ефективній ширині, розглядаються призматичні балки, а якщо йдеться про непризматичні, то розглядається як правило їх повний напружено-деформований стан. Балка, зображена на рис. 1, зустрічається в літературі доволі рідко, і здебільшого там йдеться про вирішення задач, не пов'язаних із приведеною шириною. Однією з праць, де проаналізовано напружений стан вищезгаданої балки, $є$ [1]. Цінністю цієї роботи $є$ те, що рекомендації щодо розрахунку приведеної ширини пояску в місці його зламу (на переході від меншої висоти стінки до похилої ділянки) розроблені на основі даних серійних експериментів, проведених методом електротензометрування. Проте ці рекомендації мають обмежену сферу застосування відносно параметрів вузла і можуть бути застосовані лише при пружному деформуванні тільки для місця зламу.

В інших роботах дослідження вузлів подібного типу має обмежений характер і стосується окремих задач, без систематичних узагальнень. Так, у [3] наведено огляд робіт до 2008 р., в яких розглянуто ефективність роботи пластинчатих елементів. У роботах [4-6] запропоновані оригінальні методики визначення приведеної ширини. А у [7-9] навіть запропоновані альтернативи приведеній ширині та редукційному коефіцієнту пояску. $Є$ маса інших робіт, подібних до вищезгаданих, але в них розвивається класична ідея приведеної ширини для складних конструкцій, пластинчасті елементи яких перебувають у плоскому напруженому стані або близькому до нього.

Мета дослідження полягає в обгрунтуванні та доведенні можливості застосування вищезгаданого енергетичного методу для розробки залежностей для приведеної ширини вільного пояску й оптимального проектування конструкцій на простих прикладах iз відомими аналітичними рішеннями та порівнянні його з класичним підходом для приведеної ширини.

\section{МЕТОДИ, ОБ'СКТ ТА ПРЕДМЕТ}

\section{ДОСЛІДЖЕННЯ}

Об'єктом дослідження є напружено-деформований стан вільного пояску балки зі зламом стінки і пояску, зображеної на рис. 1. Предметом дослідження є ефективна (приведена) ширина вільного пояску i, відповідно, редукційний коефіцієнт у місці переході від меншої висоти стінки до більшої. Для дослідження НДС використано метод скінченних елементів (MCE), а також деякі аналітичні рішення й емпіричні залежності.

\section{ОСНОВНИЙ МАТЕРІАЛ}

Як відомо, пояски широкополих балок перебувають у плоскому напруженому стані, тому з метою обгрунтування використання енергетичного методу проводилося дослідження плоского НДС на пластині, при дії по двох протилежних кромках дотичних симетричних самоврівноважених розподілених навантажень $p_{v x}$, як це показано на рис. 2, $a$, використовуючи аналітичне рішення у вигляді ряду, представлене в [10; 11] і МСЕ.

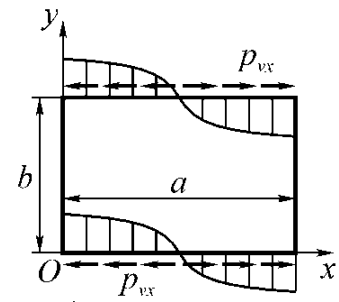

a)

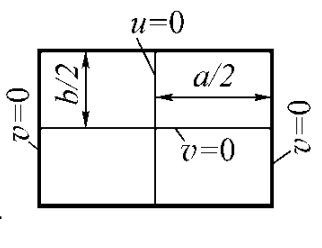

б)
Рис. 2. Досліджувана пластина

При розрахунках МСЕ використовувався трикутний плоский елемент із 6-ма точками та квадратичною апроксимацією переміщень. Попередньо були проведені чисельні експерименти по вибору розміру скінченного елементу (CE). Граничні умови (ГУ) в переміщеннях були задані, як показано на рис. 2, $\sigma$ тонкими лініями в межах поля пластини. Такі ГУ повністю відповідають полю переміщень, отримуваному за допомогою вищезгаданого аналітичного рішення [10] або [11]. Це аналітичне рішення для напружень $\sigma_{x}, \sigma_{y}, \tau_{x y}$ та переміщень $u, v$ у їх класичному позначенні, представлене в [10], має вигляд 


\section{СУДНОБУДУВАННЯ №2 2019}

$$
\begin{aligned}
& \sigma_{x}=\sum_{n=1}^{N}\left[\chi_{4 n}(1-\eta)+\chi_{4 n}(\eta)\right] \varphi_{n} \tau_{n} \sin n \pi \xi, \\
& \sigma_{y}=-\sum_{n=1}^{N}\left[\chi_{2 n}(1-\eta)+\chi_{2 n}(\eta)\right] \varphi_{n} \tau_{n} \sin n \pi \xi, \\
& \tau_{x y}=\sum_{n=1}^{N}\left[\chi_{3 n}(1-\eta)+\chi_{3 n}(\eta)\right] \varphi_{n} \tau_{n} \sin n \pi \xi, \\
& u=-\frac{b}{E} \sum_{n=1}^{N} \frac{\varphi_{n}}{\alpha_{n}}\left[\bar{\chi}_{4 n}(1-\eta)+\bar{\chi}_{4 n}(\eta)\right] \tau_{n} \sin n \pi \xi, \\
& v=-\frac{b}{E} \sum_{n=1}^{N} \frac{\varphi_{n}}{\alpha_{n}}\left[\bar{\chi}_{1 n}(1-\eta)+\bar{\chi}_{1 n}(\eta)\right] \tau_{n} \sin n \pi \xi,
\end{aligned}
$$$$
\xi=\frac{x}{a}, \quad \eta=\frac{y}{b}, \quad \gamma=\frac{b}{a}, \quad \alpha_{n}=n \pi \gamma,
$$$$
\chi_{0 n}(\eta)=\frac{\left(2+\alpha_{n} \operatorname{cth} \alpha_{n}\right) \operatorname{sh} \alpha_{n} \eta-\alpha_{n} \eta \operatorname{ch} \alpha_{n} \eta}{2 \operatorname{sh} \alpha_{n}},
$$$$
\underset{\text { де }}{\chi_{1 n}(\eta)}=\frac{\left(1+\alpha_{n} \operatorname{cth} \alpha_{n}\right) \operatorname{ch} \alpha_{n} \eta-\alpha_{n} \eta \operatorname{sh} \alpha_{n} \eta}{2 \operatorname{sh} \alpha_{n}},
$$$$
\chi_{2 n}(\eta)=\chi_{0 n}(\eta)-\frac{\operatorname{sh} \alpha_{n} \eta}{\operatorname{sh} \alpha_{n}}, \quad \chi_{3 n}(\eta)=\chi_{1 n}(\eta)-\frac{\operatorname{ch} \alpha_{n} \eta}{\operatorname{sh} \alpha_{n}},
$$$$
\chi_{4 n}(\eta)=\chi_{2 n}(\eta)-\frac{\operatorname{sh} \alpha_{n} \eta}{\operatorname{sh} \alpha_{n}}, \quad \varphi_{n}=\frac{1}{\chi_{3 n}(0)+\chi_{3 n}(1)},
$$$$
\bar{\chi}_{1 n}(\eta)=\chi_{1 n}(\eta)+\mu \chi_{3 n}(\eta), \quad \bar{\chi}_{4 n}(\eta)=\chi_{4 n}(\eta)+\mu \chi_{2 n}(\eta)
$$$$
\tau_{n}=\tau_{1 n}=\tau_{2 n}=2 \int_{0}^{1} p_{v x} \cos n \pi \xi d \xi, \quad p_{v x}=\sum_{n=1}^{N} \tau_{n} \cos n \pi \xi .
$$

де $N$ - кількість членів ряду; $E=2 \cdot 10^{11}$ Па - модуль пружності при розтягуванні,

$\mu=0,3$ - коефіцієнт Пуассона.

Досліджувалися такі параметри пластини залежно від іiї розмірів: повна пружна енергія П, Дж; середня питома пружна енергія $\varsigma_{\text {сер }}$, Дж/ ${ }^{2}$; редукційний ко-

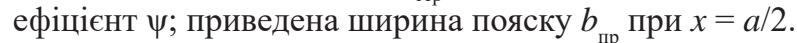

Повна пружна енергія П визначається залежністю

$$
\Pi=\iint_{D x y} \frac{1}{2 E}\left(\sigma_{x}^{2}+\sigma_{y}^{2}-2 \mu \sigma_{x} \sigma_{y}+2(1+\mu) \tau_{x y}^{2}\right) d x d y,
$$

де $D_{x y}$ - область пластини.

Середня питома пружна енергія $\varsigma_{c е р}$ визначається залежністю

$$
\varsigma_{\text {cep }}=\frac{\Pi}{a b} .
$$

Редукційний коефіцієнт $\psi$ визначається залежністю

$$
\psi=\frac{1}{E \varepsilon_{x k} b} \int_{0}^{b} \sigma_{x}(y) d y=\frac{2 \sum_{n=1}^{N} \frac{\tau_{n}}{n} \sin n \pi \xi}{\pi \gamma \sum_{n=1}^{N} \tau_{n} \varphi_{n} \sin n \pi \xi},
$$

де $\varepsilon_{x k}-$ лінійна деформація вздовж лінії з'єднання реального пояску зі стінкою;

$\sigma_{x}(y)$ - закон нормальних напружень вздовж лініі паралельній осі $y$.

Для зручності досліджень зовнішнє навантаження описувалося законом

$$
p_{v x}=\tau_{1} \cos \pi \xi
$$

де $\tau_{1}=1000 \mathrm{H} / \mathrm{M}$.

Закон дотичних навантажень у вигляді (8) дозволяє тримати при аналітичному розв'язку, як це випливає 3 (4), тільки один член ряду, що значно спрощує обчислення та підвищує їх прозорість.

Для зручності досліджень була взята пластина при фіксованому значенні довжини пластини $a=$ 1 м. Значення ширини пластини $b$ змінювалось від 0,1 м до 3 м 3 кроком 0,05м. Для кожного фіксованого значення ширини визначалися вищеназвані параметри $\Pi, \varsigma_{\text {сер }}, \psi, b_{\text {пр }}$. Розрахунки НДС пластини показали високу узгодженість результатів, отримуваних за допомогою аналітичного рішення (3) та за допомогою МСЕ. Так, розбіжність для переміщень становила не більше $0,1 \%$, а для напружень не більше $1,5-3 \%$ для характерних перерізів. Значення повних пружних енергій пластини, отриманих за допомогою (5), де напруження визначені (3) та MCE збігаються 3 дуже високою точністю (різниця між ними становить порядку 10-5\%). Редукційні коефіцієнти розраховані за (7) та МСЕ теж однакові (різниця порядку 10-4\%). Відповідні графіки залежностей $\Pi, \varsigma_{\text {сер }}, \psi, b_{\text {пр }}$ від дійсної ширини пластини $b$ представлені нижче.

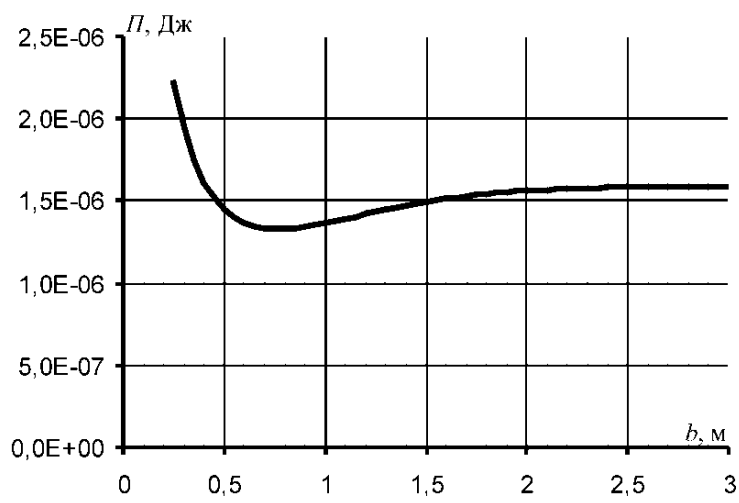

Рис. 3. Залежність повної пружної енергії П від ширини b

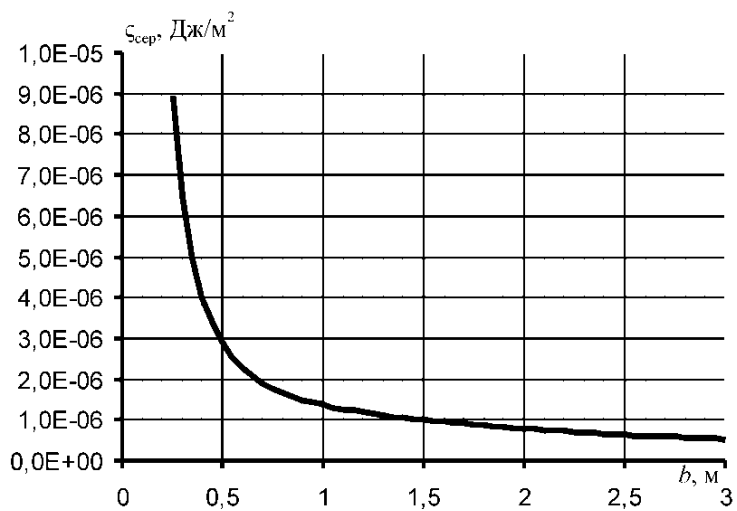

Рис. 4. Залежність середньої питомої пружної енергії цсер від ширини $\mathrm{b}$ 


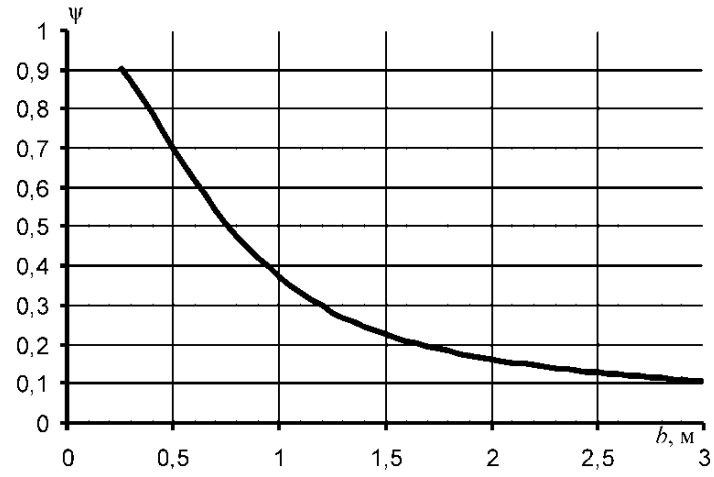

Рис. 5. Залежність редукційного коефіцієнта $\psi$ від ширини b

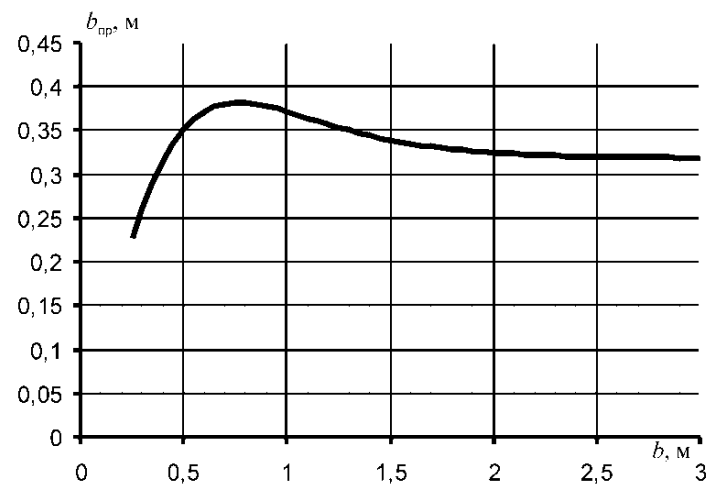

Рис. 6. Залежність приведеної ширини пояска ьпр від ширини $\mathrm{b}$

\section{ОБГОВОРЕННЯ ОТРИМАНИХ РЕЗУЛЬТАТІВ}

Як видно із вищенаведених графіків, закон приведеної ширини пояска $b_{\text {пр }}=b_{\text {пр }}(b)$ на рис. 6 найбільш подібний до закону повної пружної енергії $\Pi=\Pi(b)$ на рис. 3. Екстремуми цих функцій визначені при одній і тій же дійсній ширині пластини (пояску) $b$. Закон середньої густини пружної енергії $\varsigma_{\text {cep }}=\varsigma_{\text {сер }}(b)$, визна- чений за (6) і представлений на рис. 4, не враховує характерний «горб», властивий для закону повної пружної енергії (див. рис. 3) та приведеної ширини пояску (див. рис. 6), а характеризує лише середню густину пружної енергії, яка прямує до нуля при збільшенні ширини пластини до нескінченності. У принципі при виводі загальної формули для редукційного коефіцієнту $\psi$ (див. першу формулу (7)) неявно закладені енергетичні залежності, але до уваги взятий тільки один компонент - нормальні напруження $\sigma_{x}$. Залежність для повної енергії $\Pi=\Pi(b)$ враховує всі компоненти напруженого стану.

Як видно з вищенаведених графіків, стабілізація значення повної енергії П та приведеної ширини $b_{\text {пр }}$ відбувається при $b / a>\approx 2,0$. Це означає, що подальше збільшення ширини пояску при $b / a>2,0$ є недоцільне при законі дотичних навантажень $p_{v x}(8)$. Отже, закони повної енергії та приведеної ширини пояску дають змогу вирішувати задачі мінімальної матеріалоємності при забезпеченні необхідної міцності або несучої здатності.

\section{ВИСНОВКИ}

Вище було обгрунтовано подібність закону повної пружної енергії залежно від ширини пластини до закону приведеної ширини пластини (пояску). Показано, що енергетичний метод, як допоміжний, може бути застосований паралельно $з$ класичним, а також використаний як самостійний для створення залежностей, що пов'язують ефективну ширини пояску з параметрами вузла та проведення оптимальних досліджень.

Надалі планується дослідження поведінки пояску балки з різкою зміною висоти стінки при пружному та пружно-пластичному деформуванні та розробка відповідних методик для ефективної (приведеної) ширини пояску, застосовуючи в т. ч. ідею обговорюваного енергетичного методу, пристосованого в т. ч. i для пружно-пластичного деформування.

\section{REFERENCES}

[1] Suslov, V.P., Balandin, A.A. (1972). O reduktsionnom koeffitsiyente poyaska balki, imeyushchey izlom osi [About reduction factor of a girdle of a beam having break of an axis], Tezisy dokladov vsesoyuznoy nauchno-tekhnicheskoy konferentsii po problemam prochnosti i konstruirovaniya krupnotonnazhnykh sudov. L.: Sudostroyeniye.

[2] Sokov, V.M. (2016). Deiaki pytannia roboty vilnoho poiasku typovoho sudnovoho vuzla [Some questions of work of a free girdle of the typical ship hull assembly], Innovatsii v sudnobuduvanni ta okeanotekhnitsi: Materialy VII mizhnarodnoi naukovo-tekhnichnoi konferentsii (Mykolaiv, 12-14 zhovtnia 2016 r.). Mykolaiv : NUK.

[3] Paik, J.K. (2008). Some recent advances in the concepts of plate-effectiveness evaluation. Thin-Walled Structures, 46 (7-9), $1035-1046$.

[4] Sedlacek, G., Bild, S. (1993). A simplified method for the determination of the effective width due to shear lag effects. Journal of Constructional Steel Research, 24 (3), 155-182.

[5] Tahan, N., Pavlovic, M.N., Kotsovos, M.D. (1997). Shear-lag revisited: The use of single Fourier series for determining the effective breadth in plated structures. Computers \& structures, 63 (4), 759-767.

[6] Kirilenko, V.F. (2009). Primeneniye vidoizmenennogo resheniya Faylona v prostranstvennykh raschetakh korobchatykh balok [Applying of a modified Failon solution in three-dimensional calculations of box-like beams]. Zbirnyk naukovykh prats Ukrainskoho naukovo-doslidnoho ta proektnoho instytutu stalevykh konstruktsii imeni V.M. Shymanovskoho, № 3, $210-220$

[7] Rossi, B., Jaspart, J.P., Rasmussen, K.J. (2009). Combined distortional and overall flexural-torsional buckling of cold-formed stainless steel sections: Design. Journal of structural engineering, 136 (4), 361-369. 


\section{СУДНОБУДУВАННЯ № 2 - 2019}

[8] Schafer, B.W. (2008). The direct strength method of cold-formed steel member design. Journal of constructional steel research, 64 (7-8), 766-778.

[9] Schafer, B.W. (2002). Local, distortional, and Euler buckling of thin-walled columns. Journal of structural engineering, 128 (3), 289-299.

[10] Suslov, V.P., Kochanov, Yu.P., Spikhtarenko, V.N. (1972). Stroitelnaya mekhanika korablya i osnovy teorii uprugosti [Structural mechanics of ship and basis of theory of elasticity]. L.: Sudostroyeniye. [in Russian].

[11] Timoshenko, S.P., Goodier, J.N. (1951). Theory of Elasticity. New York, Toronto, London: McGrow Hill Book Company.

\section{СПИСОК ВИКОРИСТАНОЇ ЛІТЕРАТУРИ}

[1] Суслов, В.П., Баландин, А.А. (1972). О редукционном коэффициенте пояска балки, имеющей излом оси. Teзисы докладов всесоюзной научно-технической конференции по проблемам прочности и конструирования крупнотоннажных судов. Ленинград : Судостроение.

[2] Соков, В.М. (2016). Деякі питання роботи вільного пояску типового суднового вузла. Інноваиії в суднобудуванні та океанотехніці: Матеріали VII міжнародної науково-технічної конференщї (Миколаїв, 12-14 жовтня 2016 р.). Миколаїв : НУК.

[3] Paik, J.K. (2008). Some recent advances in the concepts of plate-effectiveness evaluation. Thin-Walled Structures, 46 (7-9), 1035-1046.

[4] Sedlacek, G., Bild, S. (1993). A simplified method for the determination of the effective width due to shear lag effects. Journal of Constructional Steel Research, 24 (3), 155-182.

[5] Tahan, N., Pavlovic, M.N., Kotsovos, M.D. (1997). Shear-lag revisited: The use of single Fourier series for determining the effective breadth in plated structures. Computers \& structures, 63 (4), 759-767.

[6] Кириленко, В.Ф. (2009). Применение видоизмененного решения Файлона в пространственных расчетах коробчатых балок. Збірник наукових праць Украӥнського науково-дослідного та проектного інституту сталевих конструкиій імені В.М. Шимановського. № 3. С. 210-220.

[7] Rossi, B., Jaspart, J.P., Rasmussen, K.J. (2009). Combined distortional and overall flexural-torsional buckling of cold-formed stainless steel sections: Design. Journal of structural engineering, 136 (4), 361-369.

[8] Schafer, B.W. (2008). The direct strength method of cold-formed steel member design. Journal of constructional steel research, 64 (7-8), 766-778.

[9] Schafer, B.W. (2002). Local, distortional, and Euler buckling of thin-walled columns. Journal of structural engineering, 128 (3), 289-299.

[10] Суслов, В.П., Кочанов, Ю.П., Спихтаренко, В.Н. (1972). Строительная механика корабля и основы теории упругости. Ленинград : «Судостроение».

[11] Timoshenko, S.P., Goodier, J.N. (1951). Theory of Elasticity. New York, Toronto, London : McGrow Hill Book Company. 